\title{
Introduction to the special issue in honor of Agustín Maravall
}

\author{
Gabriele Fiorentini $^{1}$ - Gabriel Perez Quiros ${ }^{2}$
}

Published online: 14 March 2016

C The Author(s) 2016. This article is published with open access at Springerlink.com

I desire to live in peace and to continue the life I have begun under the motto "to live well you must live unseen" (R. Descartes)

This volume brings together some of the papers presented at the Conference "Celebrating 25 years of TRAMO-SEATS and the 70th Birthday of Agustín Maravall" held in Agustín Maravall's honor at the Bank of Spain in March 2014. At least one of the contributor of each paper is an Agustín's coauthor or long-term friend. The conference put together outstanding researchers from all over the world including the University of Princeton, Chicago, Cambridge, Bruxelles, Amsterdam, the European University Institute, Carlos III, Autonoma and CEMFI of Madrid as well as the Federal Reserve Bank of Chicago, the US Bureau of the Census, Eurostat, the UK Organization of National Statistics, the Bundesbank, France INSEE, the Belgium Central Bank, Statistics Sweden and Italy ISTAT among others. In his speech of acceptance to the Rey Juan Carlos prize in economics Agustín affirmed that the conference was "one of the most emotional moments of my life" and this alone is sufficient for rewarding our effort and honor in organizing the conference and editing this special issue.

The ideas expressed here are those of the authors and do not necessarily reflect the position of the Banco de España or the Eurosystem.

\footnotetext{
$凶$ Gabriele Fiorentini fiorentini@disia.unifi.it

$凶$ Gabriel Perez Quiros gabriel.perez@bde.es

1 University of Florence, Florence, Italy

2 Banco de España, Madrid, Spain
} 
After spending the most part of his childhood in France, Agustín returned to Madrid and obtained a Ph.D. in agricultural engineering at the Universidad Complutense. He worked at the Ministry of Agriculture where he was in charge of solving quantitative problems related to forecasting and asset allocation, problems that required some knowledge of economics and econometrics. In 1971 he moved to the US to enter the Ph.D. program in Economics at the University of Wisconsin in Madison. During that period he came across the studies of George Box on the ARIMA modelling of economic time series. After completion of his Ph.D. he worked for the Board of Governors of the Federal Reserve System in Washington where he witnessed the failure of large macro econometrics models with thousands of equations. In 1979 he was back in Madrid at the Bank of Spain where he worked until his formal retirement in 2014 with an important parenthesis between 1989 and 1996 when he was full professor at the Department of Economics of the European University Institute in Florence.

Even if the fame and success of Agustín are inextricably linked to the program TRAMO-SEATS he has made several seminal contributions in the field of time series econometrics which are reflected in his papers published in the most important international journals. His work is widely know and cited, in this short introduction we will summarize some of his contributions.

We begin with two papers with David Pierce where they show how knowledge of the future would change our current vision of the present. Specifically they analyze the effect of revision errors on short-run monetary policy in the US. The decisions of the Federal Open Market Committee are based on the most recent seasonally adjusted monetary aggregate data which are unavoidably subject to revisions until the final optimal two-sided filter can be applied. They found that the proportion of times that a preliminary figure was misleading during the period of the seventies was close to 40 per cent. Reassuring enough they also found that revision errors, although large, had a small effect on the setting of the targets.

In an earlier paper he extended the work of Clive Granger on bilinear models and proposed a simple diagnostic check on the squared residuals of an ARIMA model to detect nonlinearities and higher order dependencies. The idea is simple, in a linear Gaussian stationary process the autocorrelations of the squares are equal to the squared autocorrelations of the levels and, thus, large values of the former are indication of some nonlinear structure. After the advent of models for conditional heteroskedasticity, this simple check has become a standard in applications to financial data.

The production of Agustín on ARIMA model based signal extraction is vast and insightful. He has papers on the features and issues of a model based decomposition, on the specification of the unobserved components and their identification as well as the associated estimation errors. In another paper with David Pierce on the prototypical seasonal adjustment model they describe the decomposition for the simplest possible structure that admits a trend plus seasonal plus noise decomposition thus shedding light on many issues that would be less apparent in more complex models. 
With his former student Christophe Planas they analyze signal plus nonsignal two component models. They are able to precisely relate the components estimation errors with the identification scheme and find that the estimation error is always minimized at the canonical decomposition. The works of Agustín on the properties of the component estimators are very influential. He explains clearly the distinction between the dynamics of an unobserved component and those of the component estimator which are inevitably different. In one of this papers he puts forward what we like to term as the Maravall's critique. Agustín derives the properties of the filters for the trend and the seasonally adjusted series and finds that in general the component estimator is not strictly invertible. This has several important and non trivial implications for empirical studies that employ seasonally adjusted data in unit root testing and VAR model fitting.

He has also many papers on REGARIMA models, most of which in collaboration with Victor Gómez, where he develops procedures to efficiently estimate ARIMA models with special effects and missing data and to detect and correct various type of outliers. He has paid special attention to the problem of automatic model identification and detection of outliers and has come out with simple solutions to complex problems. For instance, his ideas on settling the optimal orders of differencing to achieve stationarity are rather unconventional but tremendously powerful and always ends up providing the most reasonable solution. As we shall see, this line of research is critical to the success and widespread use of the program TRAMO-SEATS.

In a series of papers with his former student Regina Kaiser they give a model based interpretation to the popular HP detrending filter. They also propose a modification that improves the properties of the estimator at both ends of the series by deriving the optimal truncated filter based on the appropriate forecast function.

TRAMO-SEATS is undoubtedly the main reason for which Agustín is known worldwide. The program has thousands of users in National Statistical Institutes, Central Banks, International Organizations, private enterprizes and academia all over the world. TRAMO-SEATS has been incorporated into many statistical packages and also many interfaces has been developed. Agustín has been invited and has travelled in more than seventy countries, to give courses about TRAMO and SEATS and their usage. There is no reason to describe here the features of the program, the reader can refer to the numerous Agustín publications, documents and user guides. We would rather sketch what in our opinion are Agustín merits and the keys of this success story:

1. Agustín was fascinated by the AMB (Arima Model Based) approach to unobserved components. He understood and foresaw the enormous potentiality of the method as a valid alternative to ad-hoc filtering. He has then made several important improvements to the method and has been crucial to the dissemination of the ideas behind the decomposition of an observed time series into components with clear and interpretable statistical properties. Without Agustín the early studies of Box, Hillmer, Tiao, Bell, Cleveland and Burman would have remained a nice 
collection of papers of the late seventies and early eighties with little impact on the profession.

2. The AMB approach requires the identification of an ARIMA model for the series at hand and in addition many real time series need pre-adjustment before ARIMA models can be assumed due the possible presence of outliers, calendar effects and missing observations. Agustín clearly understood that a reliable and efficient automatic model identification procedure was needed for the large-scale use of the method. He has dedicated a lot of efforts in deriving and implementing the automatic procedure and his recent research aims at providing statistically rigorous evidence on the validity of the automatic procedure implemented in TRAMO when it is applied to thousands of series.

3. Before TRAMO-SEATS the prevailing method for seasonal adjustment was the X11 program and its extensions which were developed at the US Bureau of Census and are based on a battery of ad-hoc filters. Even if Agustín was firmly convinced about the validity of the AMB approach he studied in details the statistical properties of the X11 filters and looked for similarities rather than differences. He was always comparing results rather than criticizing. This attitude together with the insight and open-mindedness of David Findley has converted their encounter into a very fruitful collaboration rather than a conflict and has contributed to the development of both TRAMO-SEATS and X11 which in his latest version has incorporated many of the features of TRAMO-SEATS.

4. He has always been respectful and responsive with the program users and tried to solve all their doubts and problems. More importantly though he is the first, more critical and more demanding user and debugger of its own programs. He is very rigorous and he never succumbed to the temptation of implementing a solution of which he was not fully convinced.

5. "Only you can do it but you cannot do it alone”. In his journey Agustín has been accompanied by many people that to a different extent have contributed to the outcome of his project. In addition to Victor Gómez which we mentioned above we would like to recall his assistants at the Bank of Spain and the EUI, and in particular Gianluca Caporello who has been "his" programmer for almost thirty years. Gianluca joined Agustín in 1990 and never abandoned him. Last but by no means least another important role has been played by the patience, support and understanding of Agustín family.

Agustín has also been a mentor for many people. He spent seven years as full professor at the EUI in Florence where he left a lasting mark. His course on introductory inference statistics for graduate students was very popular and widely attended. He also supervised several Ph.D. dissertations. His former students are now working in important international institutions like the International Monetary Fund, the World Bank, the European Central Bank and the Joint Research Center of the European Commission while only two of them are in academia which is a clear indication of 
Agustín positive attitude toward solving problems with important practical implications and his aversion to pure theoretical exercises with no practical implications. It is not surprising that a former student of Agustín when facing a nontrivial empirical problem would pose himself the following question: "What would Agustín do in a situation like this?".

The contributions of Agustín to the scientific advances in economics and statistics has been recognized in his own country and abroad. In 2004 Agustín was awarded the Julius Shiskin Award for Economic Statistics for outstanding leadership and contributions to methods, software, training, and consultation for model-based seasonal adjustment and its acceptance by national statistical offices and central banks. The next year he won the Jaime I prize in Economics and in 2006 he also received the "Premio Galicia the Estadística". Finally in 2014 Agustín was awarded the "Premio Rey Juan Carlos de Economía" for his contribution in the field of economic statistics and in particular for his work in time series analysis for which he is considered one of the world leading experts. Agustín is also fellow of the American Statistical Association and of the Journal of Econometrics.

The structure of the issue is as follows. The first paper, "Illuminating ARIMA Model-Based Seasonal Adjustment with three Fundamental Seasonal Models" by David F. Findley, Demetra P. Lytras and Agustín Maravall, presents, starting from the first order seasonal autoregressive model, informative formulas for two and three components decompositions of seasonal time series, throwing some light, for example, to the finding of negative sample autocorrelation at the seasonal lag of the differenced seasonally adjusted series as being a inevitable result of removing a seasonal component whose calendar month subseries are smooth. These decompositions are of key importance to provide uncertainty intervals for growth rates, of special interest for real-time economic analysis. The second paper, "On Some Remarks about SEATS Signal Extraction", by Guy Melard, the author shows all the details of the output of SEATS, allowing the reader to formally understand all the results of the adjustment using SEATS. The author provides with a couple of details to improve the output of SEATS that could provide some hints for future versions of the SEATS software. The third paper, "Robust Time Series Models with Trend and Seasonal Components" by Michele Calvano, Andrew Harvey and Alessandra Luati, shows how to deal with outliers in models derived from a Student-t and EGB2 models, in particular, the paper proposed the dynamic conditional score t model. The paper also shows how the method can be used as the basis for seasonal adjustment procedures. Finally, the paper illustrates these results for the time series of number of tourist in Spain. The fourth paper, "Neglected Serial Correlation Tests in UCARIMA models" by Gabriele Fiorentini and Enrique Sentana proposes computationally simple test of neglected autocorrelation in unobserved components models. They carefully explain the test in practice in order to provide the reader with a clear rule to be applied directly. They also provide the properties of their test and its finite sample reliability with Monte Carlo simulations. 
Finally, the fifth paper, "Identification of asymmetric conditional heteroscedasticity in the presence of outliers" by Angeles Carnero, Ana Perez and Esther Ruiz, shows that outliers can severely affect the identification of the asymmetric response of volatility to shocks of different signs when those responses are calculated based on the sample cross-correlation between past and squared returns. They propose the use of robust cross-correlations, illustrating their results with empirical applications.

In concluding, there is a number of people that we would like to thank. First the Banco de Espańa who hosted and financed the conference and in particular Juan Francisco Jimeno head of the modelling and macroeconomic analysis division. We would also like to thank all the conference speakers, discussants and participants as well as the anonymous referees for their reviews. We are also indebt with Enrique Sentana who shared with us the responsibility of organizing the conference and the former and present editors of SERIEs Victor Aguirregabira and Nezih Guner for their support and patience with our tardiness in processing the papers. Our last thank goes to Samuel Bentolilla for his invaluable support and advice. He acted behind the scenes as a promoter and as a leader of the fans for the organization of the conference and of this special issue.

\section{Selected works of Agustín Maravall in reverse chronological order}

Optimal Signal Extraction with Correlated Components (joint with S. McElroy Tucker), Journal of Time Series Econometrics, 6(2), 237-273, 2014.

Applying and Interpreting Model-based Seasonal Adjustment. The Euro-area Industrial Production Series (joint with Domingo Pérez), in W.R. Bell, Scott H. Holan, and T.S. McElroy (eds.) "Economic Time Series: Modeling and Seasonality”, New York: CRC Press, 2012.

Temporal aggregation, systematic sampling, and the Hodrick-Prescott filter (joint with A. Del Rio), Computational Statistics \& Data Analysis, 52(2), 975-998, 2007.

An application of the TRAMO-SEATS automatic procedure; direct versus indirect adjustment, Computational Statistics \& Data Analysis, 50(9), 2167-2190, 2006.

Combining filter design with model-based filtering with an application to businesscycle estimation (joint with R. Kaiser), International Journal of Forecasting, 21(4), 691-710, 2005.

Seasonal outliers in time series (joint with R. Kaiser), Journal of the Inter-American Statistical Institute, 15, 101-142, 2003. 
Measuring business cycles in economic time series (joint with Regina Kaiser). Lecture Notes in Statistics, 154, NY: Springer-Verlag, 2001.

Automatic modelling methods for univariate series (joint with V. Gomez), in "A course in Time Series Analysis", D. Pea, D. G. Tiao and R. S. Tsay. (eds.), NY: J. Wiley and Sons, 171-201, 2001.

Estimation of the business cycle: A modified Hodrick-Prescott filter (joint with R. Kaiser), Spanish Economic Review, 1(2), 175-206, 1999.

Estimation error and the specification of unobserved component models (joint with C. Planas), Journal of Econometrics, 92(2), 325-353, 1999.

Short-term Analysis of Macroeconomic Time Series in A. Kirman and L. A. Grard Varet, eds., "Economics: Beyond the Millennium", Oxford: Oxford University Press, 244-272, 1999.

Missing observations in ARIMA models: Skipping approach versus additive outlier approach (joint with V. Gomez and D. Pena), Journal of Econometrics, 88(2), 341-363, 1998.

New Capabilities and Methods of the X-12-ARIMA Seasonal-Adjustment Program: Comment, Journal of Business \& Economic Statistics, 16(2), 155-60, 1998.

Unobserved Components in ARCH Models: An Application to Seasonal Adjustment (joint with G. Fiorentini), Journal of Forecasting, 15, 175-201, 1996.

Unobserved Components in Economic Time Series in H. Pesaran and M. Wickens (eds.), The Handbook of Applied Econometrics, chap. 1, 12-72. Oxford: Basil Blackwell, 1995.

Use and Misuse of Unobserved Components in Economic Forecasting Journal of Forecasting, 13, 157-178, 1994.

Encompassing univariate models in multivariate time series: A case study (joint with A. Mathis), Journal of Econometrics, 61(2), 197-233, 1994.

Estimation, prediction and interpolation for nonstationary series with the Kalman filter (joint with V. Gmez), Journal of the American Statistical Association, 89, 611-624, 1994. 
Stochastic linear trends: Models and estimators, Journal of Econometrics, 56(12), 5-37, 1993.

On the dynamic structure of a seasonal component, Journal of Economic Dynamics and Control, 13(1), 81-91, 1989.

A note on minimum mean squared error estimation of signals with unit roots, Journal of Economic Dynamics and Control, 12(2-3), 589-593, 1988.

A note on identification of multivariate time-series models, Journal of Econometrics, 16(2), 237-247, 1987.

A Prototypical Seasonal Adjustment Model (joint with D. A. Pierce) Journal of Time Series Analysis, 8, 177-193, 1987.

Minimum Mean Squared Error Estimation of the Noise in Unobserved Component Models, Journal of Business \& Economic Statistics, 5(1), 115-120, 1987.

Descomposicion de Series Temporales: Especificacion, Estimation e Inferencia; con una Aplicacion a la Oferta Monetaria en Espana (with discussion), Estadistica Espanola, 114, 11-69, 1987.

The Transmission of Data Noise into Policy Noise in U.S. Monetary Control (joint with D. A. Pierce), Econometrica, 54(4), 961-979, 1986

Una medida de volatilidad en series temporales con una aplicacin al control monetario en Espana (joint with S. Bentolilla), Investigaciones Economicas, 10(1), 185-199, 1986.

An application of model-based estimation of unobserved components, International Journal of Forecasting, 2(3), 305-318, 1986.

Revisions in ARIMA Signal Extraction Journal of the American Statistical Association 81, 395, 736-740, 1986.

On Structural Time Series Models and the Characterization of Components, Journal of Business \& Economic Statistics, 3(4), 350-355, 1985.

Issues Involved with the Seasonal Adjustment of Economic Time Series: Comment, Journal of Business \& Economic Statistics, 2(4), 337-339, 1984. 
Preliminary-Data Error and Monetary Aggregate Targeting (joint with D. A. Pierce), Journal of Business \& Economic Statistics, 1(3), 179-186, 1983.

An Application of Nonlinear Time Series Forecasting, Journal of Business \& Economic Statistics, 1(1), 66-74, 1983.

Effects of alternative seasonal adjustment procedures on monetary policy, Journal of Econometrics, Elsevier, vol. 14(1), pages 115-136, 1980.

Identification of the Dynamic Shock Error Model: The Case of Dynamic Regression (joint with D.J. Aigner) in D. J. Aigner and A. S. Goldberger (eds.), "Latent Variables in Socioeconomic Models”, Amsterdam: North Holland, 1977.

A note on three-stage least squares estimation, Journal of Econometrics, 4(4), 325-330, 1976.

Open Access This article is distributed under the terms of the Creative Commons Attribution 4.0 International License (http://creativecommons.org/licenses/by/4.0/), which permits unrestricted use, distribution, and reproduction in any medium, provided you give appropriate credit to the original author(s) and the source, provide a link to the Creative Commons license, and indicate if changes were made. 